knowledge of the radio markets there is available. In India, where the transmitters may be many hundreds of miles apart, medium-wave broadcasts are not of very much use, except for local listening-in areas near the large towns. They cater mainly for the local inhabitants and native listeners, and the value of the programme transmitted from one town may be of very little use in an adjacent area. The European listener abroad wants to hear programmes and news from his home country, and for this reason he has to rely on short-wave listening. The most used wavelengths for this purpose are in the 13-, 16- and 19-metre bands, which give reliable services over very long distances for the greater part of the year, while certain other stations work on 30-, 60- and 90-metre bands. The exported radio receiver therefore, in addition to withstanding tropical conditions, should cover all wave-bands from 13 metres to 90 metres, and also medium waves between 200 metres and 330 metres.

\section{Infra-Red Radiation in Industry}

A PAPER on "Infra-Red Radiation and Equipment : their Application to Industrial Processes", read recently by Mr. R. Maxted before the Illuminating Engineering Society, emphasizes that the technique of radiant heating depends on direct experiment rather than upon an understanding of wave-length effects, properties of materials, etc., although a knowledge of the spectral characteristics of the materials is necessary if optimum combinations of wave-bands and materials are desired. Transformation into sensible heat is one effect of the absorption of radiant energy, and radiant heating depends entirely upon this effect, the energy absorbed by the material being instantly converted into heat upon exposure to radiation. The incident energy is partially reflected, transmitted and absorbed when any substance is irradiated, the magnitude of each effect ranging throughout the electromagnetic spectrum with any given material. The direct effect of absorption is that energy is re-radiated at longer wavelengths, change of structural state takes place, or sensible heat is produced within the absorbing sub. stance.

Radiant heating is usually employed for dehydration, enamel stoving, or other change-of-state phenomena, and it is believed that the practical results obtained are solely due to heat application and not to any structural change arising from the direct action of radiation. Further developments may conceivably lead to the utilization of spectral effects but present-day practice aims at applying heat. It should be noted, however, that while interest centres in the thermal effects of absorption, the material receiving heat treatment is not necessarily the absorbing substance; an enamelled metal sheet, for example, may be irradiated from the back, or a transparent lacquer may be indirectly heated by absorption in the under surface.

\section{Summer School in Human Biology}

DURING the last year, the Educational Advisory Board of the British Social Hygiene Council has arranged, in co-operation with local education authorities in different parts of the country, refresher courses in biology for teachers. These were primarily designed to help to equip teachers with a background of biological knowledge, to undertake, in the schools, courses similar to the School Leaver's Courses proposed by the Board. In several areas teachers attending these lectures have expressed a wish for a further course of practical work, and to meet this demand, and that of other teachers, a summer school in human biology has been arranged to be held in Cambridge during August 5-19.

The school is planned to be of help to teachers in junior and senior schools and the junior forms of secondary schools. Each morning there will be a lecture on some biological topic, followed by practical laboratory work. The practical work will consist mainly of fairly simple experiments and demonstrations of such a nature as to be of use in schools where comparatively little equipment is available. In the afternoons there will be organized excursions to places of interest such as various research laboratories and biological museums and institutes. After tea each day there will be seminars at which practical teaching problems will be discussed, and there will be a display of biological films and textbooks.

Most evenings after dinner will be devoted to lectures, by eminent biologists, on the social implications of biology. Accommodation will be provided in one of the colleges for both men and women. There will be free time in which the members of the school will be able to visit the colleges and other places of architectural and natural interest. Further details may be obtained from the Education Officer, British Social Hygiene Council, Tavistock House South, Tavistock Square, W.C.1.

\section{Food and Nutritional Needs}

The Nutrition Society has arranged a whole-day conference on "Food Production and Distribution in Relation to Nutritional Needs" to be held on February 28, beginning at 10.30 a.m., at the London School of Hygiene and Tropical Medicine. Papers will be read by Sir John Orr ("The Agricultural Implications of a Food Policy Based on Nutritional Needs"), Dr. N. C. Wright ("Rival Claims of Animals and Man for Food"), Mr. E. T. Halnan ("Animals as Food Converters") and Sir John Russell ("Planning for Agricultural Production"). Among those who have agreed to participate in the discussion are Prof. A. W. Ashby, Sir Joseph Barcroft, Mr. A. N. Duckham, Prof. H. D. Kay and Dr. T. F. Macrae. Sir Wilson Jameson (chief medical officer, Ministry of Health) will take the chair at the morning session. Provisional arrangements have been made for further meetings to discuss, among other topics, (1) "The Preparation of Food in Wartime with Special Reference to Collective Feeding", and (2) "Nutritional Requirements for Optimum Health". Further information about the Nutrition Society can be obtained from the Hon. Secretary, Dr. Leslie J. Harris, Dunn Nutritional Laboratory, Milton Road, Cambridge.

\section{The Newton Tercentenary}

Newton was born on Christmas Day, 1642. The Physical Society will celebrate the tercentenary of his birth by holding a special meeting at which an address will be delivered dealing with the life, work and influence of Newton. The lecturer will be Prof. E. N. da C. Andrade, Quain professor of physics in the University of London. Details of the meeting will be announced later. 